\title{
My company is green, so am I: the relationship between perceived environmental responsibility of organisations and government, environmental self-identity, and pro-environmental behaviours
}

\author{
Ellen van der Werff $\cdot$ Linda Steg $\cdot$ Angela Ruepert
}

Received: 3 June 2020 / Accepted: 26 April 2021 / Published online: 10 June 2021

(C) The Author(s) 2021

\begin{abstract}
To reduce environmental problems, citizens, governments, and organisations need to take action to reduce their environmental impact. In the current paper, we tested if and how perceived environmental responsibility of organisations and government is related to pro-environmental behaviour and acceptability of pro-environmental policies among employees, customers, and citizens. We hypothesised that the stronger perceived environmental responsibility of organisations and government, the stronger the environmental self-identity of employees, customers, and citizens because they are a part of that organisation. We hypothesised that a stronger environmental self-identity, in turn, is positively related to a range of pro-environmental actions as well as acceptability of pro-environmental policies. We tested our hypotheses in three studies. We found that a stronger perceived environmental responsibility of organisations is indeed related to a stronger environmental self-identity among employees and customers of the organisation. A stronger environmental self-identity was in turn related to a range of pro-environmental actions. An alternative explanation for our findings is that those with a stronger environmental self-identity are more likely to become a customer at an organisation with a strong perceived environmental responsibility.
\end{abstract}

E. van der Werff $(\bowtie) \cdot$ L. Steg · A. Ruepert

University of Groningen, Grote Kruisstraat 2/1,

9712 TS Groningen, Netherlands

e-mail: ellen.van.der.werff@rug.nl
However, we found support for our hypotheses among those who chose and among those who did not freely choose to be a customer of the organisation, suggesting that the alternative explanation does not fully explain our findings. Furthermore, we found that citizens report a stronger environmental self-identity when perceived environmental responsibility of their government is stronger. A stronger environmental self-identity was in turn related to a higher acceptability of policies aiming to promote energy savings. Our findings are in line with social identity theory, which states that people partly infer how they see themselves based on the groups to which they belong. Furthermore, our findings have important practical implications for organisations and governments aiming to promote pro-environmental behaviour. Specifically, if organisations and government reduce their environmental impact and clearly communicate this, citizens, employees, and customers may also be more likely to do so.

Keywords Perceived environmental responsibility . Environmental self-identity · Pro-environmental behaviour

\section{Introduction}

Climate change is causing serious environmental problems such as loss of biodiversity, the decline of coral reefs, and the rising of sea levels (IPCC, 2018). 
To tackle these problems, it is important that many different actors take action to minimise their environmental impact, including citizens, governments, and organisations. For example, organisations need to reduce their environmental impact, and citizens need to save energy, adopt electric vehicles and use them in a sustainable way, and adopt pro-environmental behaviour in general. Furthermore, governments need to implement pro-environmental policies that are acceptable to the public. To achieve this, social scientists are needed to understand how to motivate these actors to minimise their environmental impact (Sovacool, 2014). Social scientists can study which factors influence whether people take action to reduce their environmental impact (Victor, 2015). Based on this, policy-makers or organisations can implement effective interventions or policies to promote pro-environmental behaviour. Importantly, the actions and measures taken by organisations may influence the actions of those who are part of the organisation. Likewise, the actions and measures taken by governments may influence the environmental actions of their citizens. In the current paper, we study how the extent to which people think their organisations or governments try to reduce environmental impact may influence pro-environmental behaviour and acceptability of environmental policies of employees, customers, and citizens.

Research suggests that the more employees perceive the organisation where they work to reduce its environmental impact, the more likely it is that the employees engage in pro-environmental behaviour at work (Dahiya, 2020; Norton et al., 2014; Ruepert, et al., 2017). For example, employees are more likely to fulfil their tasks in an environmentally friendly way, but also more likely to save energy or recycle at work the more they perceived their organisation to reduce its environmental impact. Particularly, the extent to which people perceive an organisation to endorse corporate environmental responsibility seems to influence behaviour, more so than the actual level of corporate environmental responsibility (De Vries et al., 2015). Therefore, in the current paper, we focus on perceived corporate environmental responsibility. Although perceived corporate environmental responsibility is likely to be influenced by an organisation's actual corporate environmental responsibility, they may differ. However, it is yet unclear why perceived corporate environmental responsibility encourages pro-environmental actions of individual workers. In the current paper, we will test a mechanism that may explain why the extent to which employees think their organisation aims to minimise its environmental impact influences their pro-environmental behaviour.

We propose that the more people perceive their organisation to minimise its environmental impact, the more likely they are to perceive themselves as a pro-environmental person (i.e. to have a strong environmental self-identity), because they are associated with the organisation and are likely to identify with it (Fielding \& Hornsey, 2016). Our reasoning is based on social identity theory, which states that groups of which people are a part influence how people see themselves is (Tajfel \& Turner, 1979). However, to our knowledge, it has not yet been tested if perceived corporate environmental responsibility is related to environmental self-identity among those who are part of the organisation. We argue that this is likely, because if the organisation aims to minimise its environmental impact, and people are a part of the organisation, they are more likely to perceive themselves as aiming to minimise their environmental impact. Therefore, people are more likely to see themselves as a pro-environmental person. Thus, we propose that being an employee at an organisation that aims to reduce its environmental impact is likely to strengthen the extent to which you see yourself as a pro-environmental person. Specifically, we propose that perceived corporate environmental responsibility influences one's environmental self-identity.

Environmental self-identity reflects the extent to which people see themselves as a pro-environmental person. Environmental self-identity relates to a range of environmental behaviours such as conserving energy (Thøgersen, 2018; Whitmarsh and O'Neill, 2010), reducing waste, eco-shopping (Whitmarsh \& O'Neill, 2010), recycling, refraining from flying to a holiday destination (Gatersleben, et al., 2014), using green energy, choosing more sustainable products, and using paper more economically (Van der Werff, Steg, \& Keizer, 2013, 2014). Therefore, we expect that perceived corporate environmental responsibility is related to a stronger environmental self-identity, which is in turn related to different types of proenvironmental behaviour among employees of the organisation.

In addition to employees, customers of an organisation may also feel part of the organisation. Notably, 
as organisations may have many customers, it can have important practical implications if perceived corporate environmental responsibility also influences environmental self-identity and environmental behaviour among customers of organisation. Therefore, we will also test if perceived corporate environmental responsibility is related to environmental self-identity and environmental behaviour among their customers. It has indeed been argued that organisations can promote pro-environmental behaviour among its customers (Heikkurinen et al., 2019). Based on social identity theory, we hypothesise that any organisation you feel associated with may influence the extent to which you see yourself as a pro-environmental person and thereby influence your environmental behaviour. Specifically, we argue that not only employees working at the organisation but also customers of the organisation may be influenced by the extent to which they think the organisation aims to minimise its environmental impact. After all, customers may also feel associated with the organisation.

Indeed, past research supports our reasoning that organisations may influence their customers. Specifically, a study shows that perceived corporate social responsibility increases customers' donations to corporate supported non-profit organisations (Lichtenstein, et al., 2004). Furthermore, research suggests that organisations can promote pro-environmental behaviour among their customers (Elf et al., 2020). However, in this study, interventions were tested that directly targeted the behaviour of the customers; it did not aim to influence the extent to which customers see the organisation as pro-environmental. Also, a correlational study among US households suggests that the more customers believe that their electricity company is transparent about its environmental impact, the more willing the customers are to engage in pro-environmental behaviour (Vaccaro \& Echeverri, 2010). However, this study did not explicitly test whether customers are more willing to engage in environmental behaviour when perceived corporate environmental responsibility is stronger. Rather, they studied the extent to which the company is transparent about its environmental impact, which does not necessarily imply that they think the organisation aims to reduce its environmental impact. Furthermore, they did not study the underlying process. Therefore, the question remains whether perceived corporate environmental responsibility is related to a stronger environmental self-identity and thereby to more pro-environmental behaviour among customers of the organisation.

Based on social identity theory, we argue that perceived corporate environmental responsibility can influence the environmental self-identity and environmental behaviour of anyone who feels part of that organisation. Therefore, if citizens perceive their government as minimising its environmental impact, they may see themselves as more pro-environment and be more likely to act pro-environmentally. That is because citizens may feel associated with their government and, thus, internalise the environmental goals of that institution. As such, perceived governmental environmental responsibility may be related to environmental self-identity as well. Thus, governmental environmental responsibility may change the environmental behaviour of citizens by strengthening their environmental self-identity.

Research indeed suggests that citizens are more likely to engage in environmental behaviour the more they see their government or country as aiming to minimise their environmental impact. Rabinovich and colleagues (2012) showed in an experimental study that when people compare their own country to a less pro-environmental country, they are more likely to think that their own country is pro-environmental. Subsequently, they are more likely to find it important to protect the environment and engage in pro-environmental behaviour. Furthermore, when people compare their own country to a more pro-environmental country, they are less likely to think that their country is pro-environmental and are less likely to engage in pro-environmental behaviour. However, they did not study whether citizens' environmental perceptions of their country or government are related to pro-environmental behaviour of citizens via environmental self-identity. Dietz and colleagues (2015) showed that the more pro-environmental their state's government votes, the less greenhouse gas emissions are emitted in that state. However, they did not study why perceptions of the government may influence the behaviour of its citizens. We hypothesise and test if citizens' environmental self-identity and if pro-environmental preferences are stronger the more they perceive their government to reduce their environmental impact.

One alternative explanation may be that those with a stronger environmental self-identity may be more 
likely to start working or become a customer at an organisation that aims to reduce its environmental impact. Studies indeed suggest that environmental self-identity is related to eco-shopping (Whitmarsh \& O'Neill, 2010), and choosing more sustainable products (Van der Werff, Steg, \& Keizer, 2013, 2014). However, citizens do not freely choose with which local or national government they are associated; it simply depends on where one lives. Similarly, in some cases, people cannot choose which company they are a customer of. For example, in some places, people cannot choose their energy provider as it depends on where they live. In that case, environmental self-identity is not likely to influence whether one becomes a customer of this company. Therefore, we will test if perceived governmental or corporate environmental responsibility influences environmental self-identity and thereby environmental preferences and behaviour among citizens and among customers who did not choose their company. As such, we can provide evidence that perceived environmental responsibility changes environmental self-identity.

\section{Present study}

In sum, we will test if perceived environmental responsibility of organisations is related to a stronger environmental self-identity and thereby to more proenvironmental behaviour and stronger acceptability of environmental policies among those who are part of the organisation. We focus on perceived environmental responsibility of organisations and governments in our studies. Therefore, we from now on use the term perceived environmental responsibility which includes both perceived corporate environmental responsibility and perceived governmental responsibility. Previous research has shown that perceived environmental responsibility influences pro-environmental behaviour (Dahiya, 2020; Norton et al., 2014; Ruepert et al., 2017); however, it is unclear why this is the case. We address this gap in the literature and hypothesise that a stronger perceived environmental responsibility is related to a stronger environmental self-identity (Hypothesis 1). We hypothesise that environmental self-identity mediates the relationship between perceived environmental responsibility and pro-environmental behaviour (Hypothesis 2).
We will test our hypotheses in three studies: two among employees and customers of organisations and one among citizens and governments. In Study 1, we will focus on employees of organisations and their pro-environmental preferences and behaviour. We measure pro-environmental behaviour in general, as well as the sustainable use of an electric vehicle. Specifically, we measure the willingness to smart charge the electric vehicle and to use vehicle-to-grid. That way, electric vehicles can be charged with renewable energy, such as solar or wind energy, and reduce $\mathrm{CO}_{2}$ emissions (Nicolson et al., 2017). In Study 2, we will focus on customers of energy organisations and their energy use behaviour. As explained above, one could argue that customers with a stronger environmental self-identity are more likely to become a customer at an organisation that they perceive to have a stronger environmental responsibility instead of perceived environmental responsibility influencing their environmental self-identity. Therefore, to rule out this alternative explanation, we will test our reasoning among those who chose to become a customer at the organisation as well as among those who could not choose to be a customer at the organisation. In Study 3 , we will focus on citizens and examine whether the perceived environmental responsibility of their government is related to their environmental self-identity and thereby to the acceptability of environmental policies. In all studies, we expect that a stronger perceived environmental responsibility is related to a stronger environmental self-identity and that this in turn related to pro-environmental action.

\section{Study 1}

\section{Method}

\section{Participants and procedure}

Electric vehicle drivers received a newsletter of the electric vehicle charging company New Motion in the Netherlands in 2017. The newsletter included a link to an online questionnaire in Dutch on electric driving and invited them to participate in this study on electric driving. In addition to the questions used for the current analyses, the questionnaire contained questions to evaluate the service of New Motion, questions on the electric vehicle and its use. About 40,000 to 
45,000 people received the newsletter, including the link to the questionnaire, of which 2479 (a response rate of about $6 \%$ ) completed the online questionnaire. Only participants who drive an electric vehicle that is leased through their employer received the questions on perceived environmental responsibility of their company and were selected for the current analyses $(\mathrm{N}=434)$. Some organisations offer their employees the possibility to lease a car through the organisation. Due to tax benefits, leasing a car can be a financially attractive option for employers and employees. Age ranged from 23 to $73(M=50, S D=8.05)$. Of the participants, $91 \%$ was male, $8 \%$ female, while $1 \%$ did not indicate their gender. In total, $96 \%$ of the participants were from the Netherlands and $4 \%$ from Belgium. Furthermore, $33 \%$ leased a full electric vehicle and $67 \%$ a plugin-hybrid electric vehicle.

\section{Measures}

Perceived environmental responsibility We measured perceived environmental responsibility (PER) with the same three items as used in previous research (Ruepert et al.,4 2017; Study 2): "My organisation has the goal to minimalise its impact on the environment", "My organisation has implemented policy and procedures to minimalise its impact on the environment", and "My organisation has stated in its mission to implement sustainable (pro-environmental) policy". Participants could answer on a scale from 1 (totally disagree) to 7 (totally agree). The internal consistency of the scale was good $(N=434, \alpha=0.94$, $M=4.66, S D=1.77)$.

Environmental self-identity We measured environmental self-identity (ESI) with three items (Van der Werff et al., 2013): "I am the type of person who acts environmentally-friendly", "Acting environmentally-friendly is an important part of who I am", and "I see myself as a pro-environmental person". The internal consistency of the scale was good $(N=434$, $\alpha=0.93, M=4.97, S D=1.36$ ).

Sustainable use of the electric vehicle We included two indicators to assess the extent to which people use their electric vehicle in a sustainable way: smart charging (SC) and use of vehicle-to-grid technology (VTG). We explained in the questionnaire that smart charging is when one charges the electric vehicle when energy from renewable sources (e.g. wind and solar) is available. We asked participants the following question: Would you like to use smart charging? Participants could answer on a scale from 1 (definitely no) to 7 (definitely yes; $N=356, M=5.12$, $S D=1.80$ ). We explained to participants that vehicleto-grid technology is when electric vehicles temporally store energy from renewable sources and return it to the grid when needed. We asked participants "Would you like to use vehicle-to-grid?" on a scale from 1 (definitely no) to 7 (definitely yes; $N=434$, $M=4.79, \quad S D=1.85)$. We analysed these items separately.

Self-reported pro-environmental behaviour We asked participants to what extent they engage in seven environmental behaviours (PEB) on a scale from 1 (totally disagree) to 7 (totally agree). The items were based on previous studies (Whitmarsh \& O'Neill, 2010) and the interest of the organisation that sent out the newsletter. The behaviours were as follows: "I recycle my waste", "I try to save energy in my house", "I buy local and seasonal products as much as possible", "I eat meat (reverse coded)", "I grow my own vegetables/fruit", and "I collect rainwater". The internal consistency of the scale was moderate $(N=434, \alpha=0.67, M=3.56, S D=0.92)$. Cronbach's alpha increases to 0.70 when the recoded item on meat consumption is left out $(M=3.74, S D=1.01)$. In the following, we will use the scale including meat consumption because we are interested in a broad range of environmental behaviours. However, the results are similar, with slightly larger effect sizes, if the item measuring meat consumption is removed from the scale.

\section{Data analyses}

To test Hypothesis 1, we will calculate the bivariate correlation between perceived environmental responsibility and environmental self-identity. To test Hypothesis 2, we will use the PROCESS model by Hayes (2017). Specifically, we will use model 4 from the PROCESS macro to test mediation and to test if perceived environmental responsibility is related to pro-environmental behaviour via environmental selfidentity. We will use the same analysis in all three studies. 
Table 1 Correlations between perceived environmental responsibility (PER), environmental self-identity (ESI), willingness to use smart charging (SC), willingness to use vehicleto-grid (VTG), and pro-environmental behaviour (PEB)

\begin{tabular}{llllll}
\hline & PER & ESI & SC & VTG & PEB \\
\hline PER & - & & & & \\
ESI & $.40^{* *}$ & - & & & \\
SC & .07 & $.36^{* *}$ & - & & \\
VTG & .06 & $.23 * *$ & $.37 * *$ & - & \\
PEB & $.14 * *$ & $.52 * *$ & $.30^{* *}$ & $.21^{* *}$ & - \\
\hline
\end{tabular}

${ }^{* *} \mathrm{p}<.01, * \mathrm{p}<.05$

Results

We found a positive and significant correlation between perceived environmental responsibility (PER) and environmental self-identity (ESI). In line with Hypothesis 1, we found that stronger PER was associated with stronger ESI. In Table 1, we report the bivariate correlations between all variables.

As can be seen in Table 1, the preconditions to test mediation were met. That is, the independent variable (PER) was related to the mediator (ESI), and the mediator was related to all dependent variables, namely, willingness to smart charge (SC), willingness to use vehicle-to-grid technology (VTG), and selfreported pro-environmental behaviour (PEB).

We found that the stronger PER, the stronger ESI (see Fig. 1). Next, PER and ESI explain $14 \%$ of the variance in $\operatorname{SC}(F(2,353)=28.30, p<0.001)$. A stronger ESI is associated with higher SC, while PER remains not significantly related to SC when ESI is controlled for. The indirect effect of PER on SC via ESI identity $(a * b)$ is 0.16 and significant, as the $95 \%$ confidence interval does not include 0 (LLCI $=0.11$, $\mathrm{ULCI}=0.22$ ), supporting Hypothesis 2. As such, we found indirect only mediation (Zhao et al., 2010).
That means that PER is not directly related to SC but only indirectly via ESI.

PER and ESI explain $6 \%$ of the variance in VTG $(F(2,431)=12.81, p<0.001)$. The stronger one's ESI, the stronger VTG, while PER remains not significantly related to VTG when ESI is controlled for (see Fig. 1). The indirect effect of PER on VTG $(a * b)$ is 0.10 and significant, as the $95 \%$ confidence interval ranges from 0.06 to 0.16 and, thus, does not contain zero. This suggests that PER is related to V2G via ESI, supporting Hypothesis 2. We again found indirect only mediation. This means that PER is not directly related to VTG but only indirectly via ESI.

Finally, PER and ESI explain $16 \%$ of the variance in PEB $(F(2,431)=80.25, p<0.001)$. The stronger one's ESI, the stronger PEB (see Fig. 1), while the relationship between PER and PEB becomes weaker and negative when ESI is also included in the model. The indirect effect of PER on PEB via ESI $(a * b)$ is 0.12 and significant as the confidence interval does not contain 0 (LLCI $=0.08$, ULCI $=0.15$ ), supporting Hypothesis 2. We found competitive mediation, suggesting that there may be other mediators as well (Zhao et al., 2010). That means that the relationship between PER and PEB is explained by ESI; however, they may be other mediators as well.

\section{Discussion Study 1}

In Study 1, we found support for Hypothesis 1. The stronger the perceived environmental responsibility, the stronger the environmental self-identity of the employees. We also found support for Hypothesis 2: Perceived environmental responsibility is related to a stronger willingness to use the electric vehicle in a sustainable way, namely, to use smart charging and vehicle-to-grid technology, and to pro-environmental behaviours more generally, via environmental selfidentity. The findings suggest that when people work
Fig. 1 The relationship between perceived environmental responsibility, environmental self-identity and pro-environmental behaviour

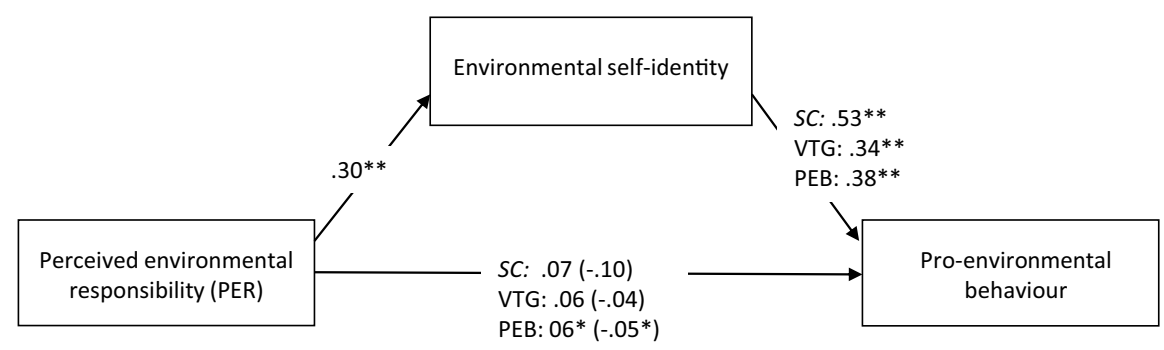


at an organization that they perceive to be pro-environmental, they are more likely to see themselves as a pro-environmental person, which in turn is related to a range of pro-environmental behaviours. We found that the strength of the relationship between perceived environmental responsibility and environmental selfidentity among employees is medium (Cohen, 1988). Furthermore, we found that perceived environmental responsibility was only indirectly related to sustainable use of an electric vehicle, via environmental self-identity. For pro-environmental behaviour in general, we found competitive mediation, suggesting that environmental self-identity mediates the relationship between perceived environmental responsibility, but other variables may also explain this relationship (Zhao et al., 2010). In Study 2, we will test if our hypotheses also apply to customers of an organisation. Furthermore, to generalise our findings, we focus on a different type of behaviour, namely, energy use.

\section{Study 2}

\section{Method}

The aim of Study 2 was to test if our hypotheses can be generalised to customers of an organisation. Importantly, we test our hypotheses among customers who chose to be a customer of the organisation and among customers who could not choose to be a customer of the organisation. That way, we can rule out the explanation that customers with a stronger environmental self-identity are more likely to become a customer at an organisation that they perceive to have a stronger environmental responsibility. Therefore, we used data from an EU project where we collected data on customers of energy companies in three European countries, namely, Italy, the Netherlands, and Switzerland. In Italy and the Netherlands, people choose to become a customer of the energy company. In Switzerland, people must be a customer of the specific energy company in their region and, as such, have no choice over their energy provider.

\section{Participants and procedure}

Utilities in the three European countries sent out the invitation for the questionnaire to their customers in
2017. Utilities in Italy (ENI), the Netherlands (Qurrent), and Switzerland (Stadtwerk Winterthur and Aziende Industriali Lugano) were selected. Customers can choose to be a customer at ENI and Qurrent, while customers of Stadtwerk Winterthur and Aziende Industriali Lugano must be a customer at this regional utility. In Italy and the Netherlands, the households received an invitation to the online questionnaire via e-mail, while in Switzerland, postal letters including a link to the questionnaire were sent out as invitations. We developed the questionnaire in English and then translated it to Italian, Dutch, and German.

In addition to the questions used for the current paper, the questionnaire contained detailed questions on one's house, energy consumption, knowledge regarding energy consumption, as well as values and norms (for details on the data collection see Daminato, Boogen, \& Van der Werff, 2018). Overall, $3.22 \%$ of the households that received the invitation to take the survey completed the survey. In Italy, 1508 participants started the survey, of which 1475 completed the survey: a response rate of $1.48 \%$. In the Netherlands, 2252 participants started the survey, of which 1923 completed the survey: a response rate of $11.85 \% .^{1}$ In Switzerland, 1477 started the survey, of which 1080 completed the survey: a response rate of $3.69 \%$.

The demographics of the samples can be found in Table 2. Overall, men are overrepresented in all countries, age is a bit higher than average, households are slightly larger than the country averages, and income is a bit higher (Eurostat, 2017).

\section{Measures}

Perceived corporate environmental responsibility We used the same items as in Study 1 to measure PER. However, this time, we mentioned the name of the utility company (e.g. "ENI/Qurrent/Stadtwerk Winterthur/Aziende Industriali Lugano has the goal to minimalise its impact on the environment"). Responses were again given on a scale ranging from 1 (totally disagree) to 7 (totally agree). The internal

\footnotetext{
$\overline{1}$ The utility in the Netherlands was relatively new and did not have many customers. Perhaps customers were therefore more likely to respond to a message from the organisation.
} 
Table 2 Overview of the demographics in Italy, the Netherlands, and Switzerland

\begin{tabular}{|c|c|c|c|c|c|c|c|c|c|}
\hline & \multicolumn{3}{|c|}{ Italy } & \multicolumn{3}{|c|}{ The Netherlands } & \multicolumn{3}{|c|}{ Switzerland } \\
\hline & $\%$ & M & SD & $\%$ & M & SD & $\%$ & M & SD \\
\hline \multicolumn{10}{|l|}{ Gender } \\
\hline Male & 69 & & & 62 & & & 64 & & \\
\hline Female & 31 & & & 38 & & & 36 & & \\
\hline Age & & 53 & 13.80 & & 49 & 14.53 & & 52 & 14.17 \\
\hline Household size & & 2.66 & 1.17 & & 2.38 & 1.12 & & 2.51 & 1.17 \\
\hline \multicolumn{10}{|c|}{ Monthly household income in euros } \\
\hline$<1500$ & 9 & & & 4 & & & 1 & & \\
\hline $1500-4500$ & 35 & & & 35 & & & 9 & & \\
\hline $4501-6000$ & 6 & & & 14 & & & 10 & & \\
\hline 60019000 & 4 & & & 11 & & & 24 & & \\
\hline $9001-12,000$ & 1 & & & 4 & & & 19 & & \\
\hline$>12.000$ & 12 & & & 4 & & & 22 & & \\
\hline Did not answer & 34 & & & 28 & & & 16 & & \\
\hline
\end{tabular}

consistency of the scale was good in Italy $(N=1496$, $\alpha=0.93, \quad M=4.93, \quad S D=1.49)$, the Netherlands $(N=2006, \alpha=0.87, M=5.59, S D=1.14)$, and Switzerland $(N=1030, \alpha=0.70, M=4.14, S D=1.25)$.

Environmental self-identity We used the same measures as in Study 1 to measure ESI. The internal consistency of the scale was good in Italy $(N=1499$, $\alpha=0.93, \quad M=6.10, \quad S D=1.03)$, the Netherlands $(N=2018, \alpha=0.89, M=5.09, S D=1.18)$, and Switzerland $(N=1031, \alpha=0.87, M=5.33, S D=1.10)$.

Energy saving behaviours Respondents indicated how often they engaged in three types of energy saving behaviours: "Running only full loads when using the dishwasher or washing machine", "Turning off the lights when leaving a room even for a short period of time", and "Completely switching off electronic

Table 3 Means and standard deviations for washing with a full load (washing), switching off the lights (lights), switching off appliances (appliances), temperature setting during the day devices (TV, computer) [no standby]", on a scale ranging from 1 (never) to 5 (always). We analysed all items separately; means and standard deviations are reported in Table 3. Furthermore, we used two self-reported behaviours focussing on energy use for heating the house: "What is the usual temperature in your living room during winter in the day-time?" and "What is the usual temperature in your living room during winter at night-time?". Participants could answer on a scale from $1\left(<16{ }^{\circ} \mathrm{C}\right), 2\left(16{ }^{\circ} \mathrm{C}\right)$, $3\left(17{ }^{\circ} \mathrm{C}\right)$ etc. to $11\left(>24{ }^{\circ} \mathrm{C}\right)$ or indicate that they did not know (Benders et al., 2006; Namazkhan et al., 2019). We recoded the values to reflect the average temperature in the living room $\left(1\right.$ was coded as $15{ }^{\circ} \mathrm{C}$ and 11 as $25{ }^{\circ} \mathrm{C}$ ). Means and standard deviations are reported in Table 3.

(temp. day), and temperature setting at night (temp. night) in Italy, the Netherlands, and Switzerland

\begin{tabular}{|c|c|c|c|c|c|c|c|c|c|}
\hline & \multicolumn{3}{|l|}{ Italy } & \multicolumn{3}{|c|}{ The Netherlands } & \multicolumn{3}{|c|}{ Switzerland } \\
\hline & $\mathrm{N}$ & M & SD & $\mathrm{N}$ & M & $\mathrm{SD}$ & $\mathrm{N}$ & M & $\mathrm{SD}$ \\
\hline Washing & 1508 & 4.28 & .97 & 2101 & 4.35 & .96 & 1027 & 4.35 & .74 \\
\hline Lights & 1508 & 4.35 & .82 & 2109 & 4.22 & .84 & 1036 & 4.09 & .81 \\
\hline Appliances & 1508 & 3.11 & 1.43 & 2110 & 3.48 & .84 & 1035 & 3.16 & 1.37 \\
\hline Temp. day & 1471 & 19.55 & 1.75 & 2101 & 19.35 & .84 & 1020 & 20.99 & 1.45 \\
\hline Temp. night & 1403 & 17.54 & 1.78 & 2096 & 16.71 & .84 & 963 & 19.09 & 1.90 \\
\hline
\end{tabular}


Results

As can be seen in Table 4, our findings support Hypothesis 1: A stronger PER is related to a stronger ESI. We found that this was the case when customers chose to be a customer at their utility, namely, in Italy and the Netherlands, as well as when customers did not choose to be a customer at their utility, namely, in Switzerland. See Table 3 for all the bivariate correlations between all variables.

The preconditions to test mediation were met in all cases. Specifically, the independent variable (PER) is related to the mediator (ESI) and that the mediator is related to all dependent variables (energy use behaviours).

We found support for Hypothesis 2 (see Fig. 2a-e). Specifically, PER and ESI explain $2 \%$ of the variance in washing with a full load in Italy $(\mathrm{F}(2$, $1489)=15.67, \mathrm{p}<0.001), 2 \%$ in the Netherlands $(\mathrm{F}(2,1992)=12.54, \mathrm{p}<0.001)$, and $3 \%$ in Switzerland $(\mathrm{F}(2,1019)=14.39, \mathrm{p}<0.001)$. The indirect effect of PER on washing with a full load $(a * b)$ is 0.03 and significant [LLCI $=0.01, \quad \mathrm{ULCI}=0.04]$ in Italy, $(\mathrm{a} * \mathrm{~b})$ is 0.03 and significant [LLCI $=0.02$, $\mathrm{ULCI}=0.04]$ in the Netherlands, and $(\mathrm{a} * \mathrm{~b})$ is 0.04 and significant $[\mathrm{LLCI}=0.02$, ULCI $=0.05]$ in Switzerland (see Fig. 2a). PER and ESI explain 3\% of the variance in switching off the lights in Italy $(\mathrm{F}(2$, $1489)=22.42, \mathrm{p}<0.001), 4 \%$ in the Netherlands $(\mathrm{F}(2,2000)=44.55, \mathrm{p}<0.001)$, and $6 \%$ in Switzerland $(\mathrm{F}(2,1027)=14.39, \mathrm{p}<0.001)$. The indirect effect of PER on switching off the lights $(a * b)$ is 0.02 and significant [LLCI $=0.01, \quad \mathrm{ULCI}=0.04]$ in Italy, $(\mathrm{a} * \mathrm{~b})$ is 0.05 and significant [LLCI $=0.04$, $\mathrm{ULCI}=0.06]$ in the Netherlands, and $(\mathrm{a} * \mathrm{~b})$ is 0.06 and significant [LLCI $=0.04$, ULCI $=0.08$ ] in Switzerland (see Fig. 2b). PER and ESI explain $4 \%$ of the variance in switching off appliances in Italy $(\mathrm{F}(2$, $1489)=29.64, p<0.001), 5 \%$ in the Netherlands $(F(2$, $2000)=55.73, \mathrm{p}<0.001)$, and $4 \%$ in Switzerland $(\mathrm{F}(2,1026)=22.36, \mathrm{p}<0.001)$. The indirect effect of PER on switching off appliances $(a * b)$ is 0.02 and significant $[\mathrm{LLCI}=0.01$, ULCI $=0.04]$ in Italy, $\left(\mathrm{a}^{*} \mathrm{~b}\right)$ is 0.05 and significant [LLCI $=0.04, \mathrm{ULCI}=0.06$ ] in the Netherlands, and $\left(\mathrm{a}^{*} \mathrm{~b}\right)$ is 0.06 and significant $[\mathrm{LLCI}=0.04, \mathrm{ULCI}=0.08]$ in Switzerland (see Fig. 2c). PER and ESI explain $1 \%$ of the variance in temperature setting during the day in Italy $(\mathrm{F}(2$, $1453)=4.72, p=0.009), 1 \%$ in the Netherlands $(F(2$,

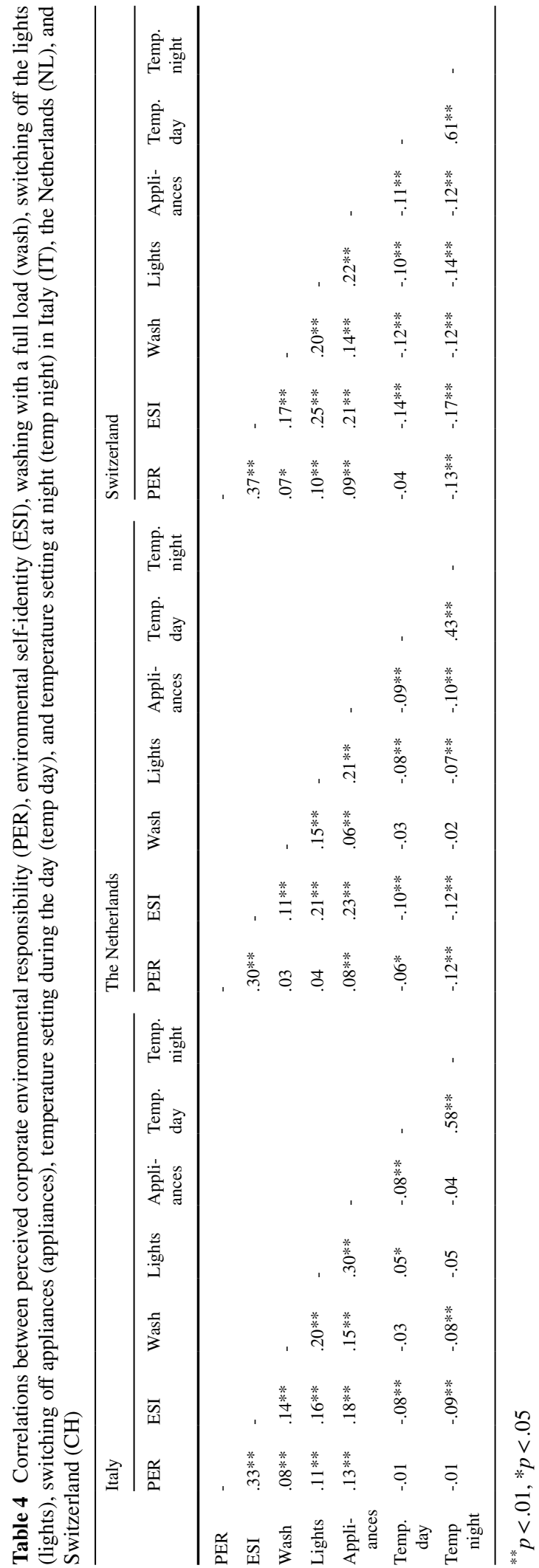


Fig. 2 The relationships between perceived environmental responsibility, environmental self-identity and energy-saving behaviours a

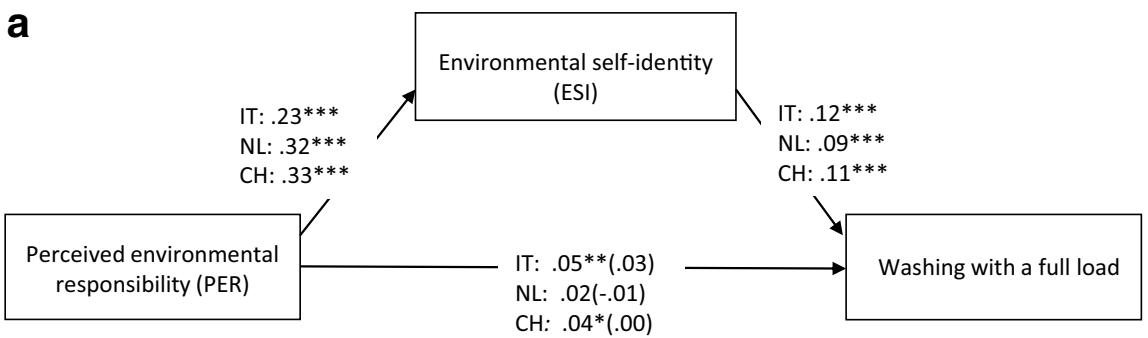

b

$\mathrm{CH}: .04 *(.00)$

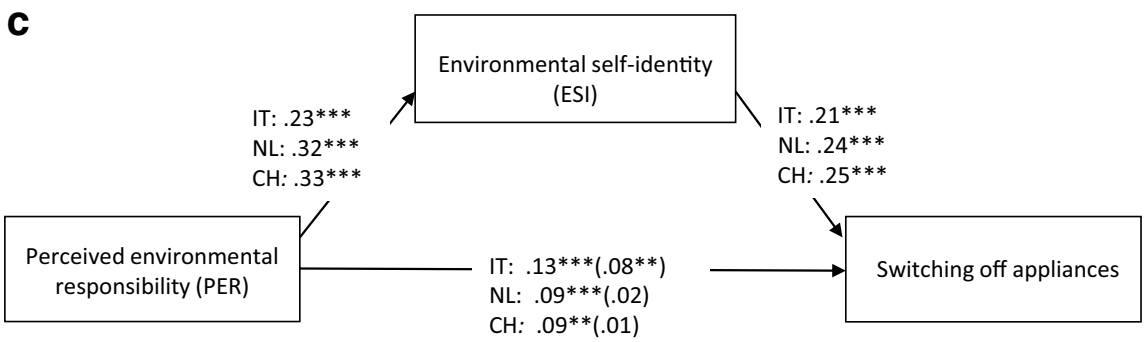

d

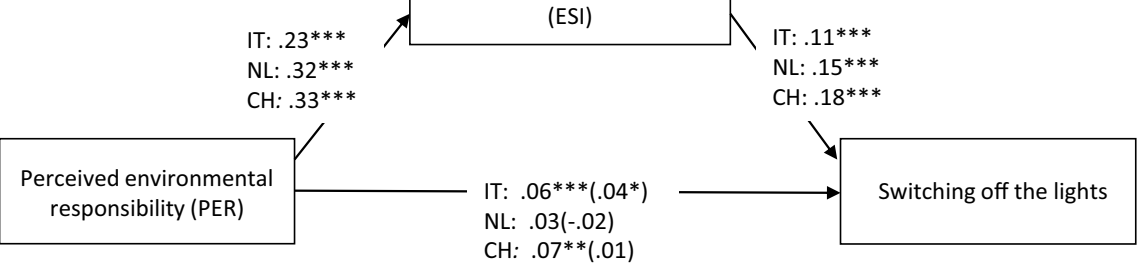

$\mathrm{CH}: .09 * *(.01)$

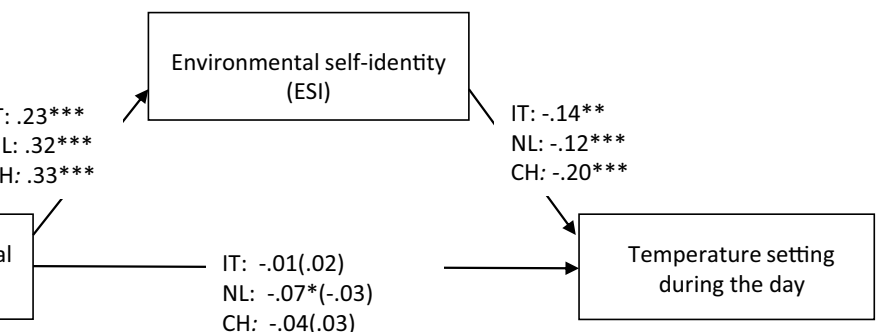

e

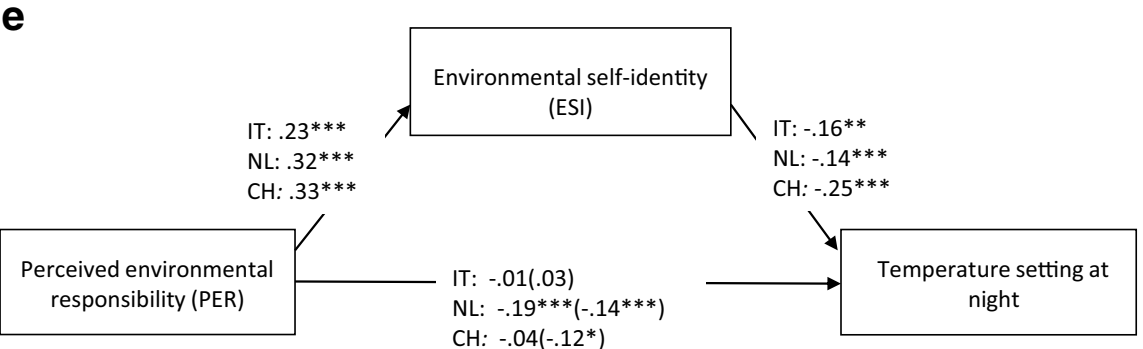


1986) $=11.64, \mathrm{p}<0.001$ ), and $2 \%$ in Switzerland $(\mathrm{F}(2,1011)=10.54, \mathrm{p}<0.001)$. The indirect effect of PER on temperature setting during the day $(a * b)$ is -0.03 and significant [LLCI $=-0.05$, ULCI $=-0.01$ ] in Italy, $(\mathrm{a} * \mathrm{~b})$ is -0.04 and significant [LLCI $=-0.06$, ULCI $=-0.02]$ in the Netherlands, and $\left(a^{*} b\right)$ is -0.07 and significant [LLCI $=-0.10$, ULCI $=-0.04]$ in Switzerland (see Fig. 2d). PER and ESI explain 1\% of the variance in temperature setting at night in Italy $(\mathrm{F}(2,1389)=5.44, \mathrm{p}=0.004), 2 \%$ in the Netherlands $(\mathrm{F}(2,1982)=22.55, \mathrm{p}<0.001)$, and $4 \%$ in Switzerland $(F(2,955)=17.42, \mathrm{p}<0.001)$. The indirect effect of PER on temperature setting at night $(a * b)$ is -0.04 and significant $[\mathrm{LLCI}=-0.06$, ULCI $=-0.02$ ] in Italy, $(\mathrm{a} * \mathrm{~b})$ is -0.04 and significant [LLCI $=-0.07$, $\mathrm{ULCI}=-0.02]$ in the Netherlands, and $\left(\mathrm{a}^{*} \mathrm{~b}\right)$ is -0.08 and significant $[\mathrm{LLCI}=-0.13, \mathrm{ULCI}=-0.04]$ in Switzerland (see Fig. 2e).

Overall, we found that ESI mediates the relationship between PER and all energy use behaviours. Again, we found that this was the case when customers choose their energy company as well as when customers did not choose to be a customer at this company. Specifically, in Italy, we found complementary mediation for switching off the lights and switching off appliances, suggesting that ESI mediates the relationship between PER and energy use behaviours, but that there may be other mediators as well. In the Netherlands and Switzerland, we found complementary mediation for temperature setting at night. As such, there may be other mediators as well (Zhao et al., 2010). In all other cases, we found indirect only mediation. These results mean that PER is not directly related to these energy use behaviour but only indirectly via ESI.

\section{Discussion study 2}

Study 2 shows that a stronger perceived environmental responsibility is related to a stronger environmental self-identity among customers of the utility company. The environmental self-identity of customers is, in turn, related to self-reported energy consumption behaviour. Interestingly, we do not only found support for our model when participants chose to be a customer of this company, but also when people did not choose to become a customer at this company. This suggests that the alternative explanation-that people with a stronger environmental self-identity are more likely become a customer of a company with a strong perceived environmental responsibility-does not fully explain our findings.

Our results show that perceived environmental responsibility not only influences employees who work at the company, as has been found in previous studies (Dahiya, 2020; Norton et al., 2014; Ruepert et al., 2017), but also the customers of a company. We again found that the relationship between perceived environmental responsibility and environmental selfidentity is medium (Cohen, 1988). We again found support for indirect only and complementary mediation. Indirect only mediation suggests that perceived environmental responsibility is only indirectly related to pro-environmental behaviour via environmental self-identity, not directly. Complementary mediation suggests that other variables may also explain the relationship between perceived environmental responsibility and pro-environmental behaviour (Zhao et al., 2010). We found that the internal consistency of the perceived environmental responsibility scale was weaker in Switzerland than in Italy and the Netherlands; however, the internal consistency of the scale was still sufficient. Perhaps due to translation issues, the internal consistency was lower in Switzerland.

\section{Study 3}

Method

The aim of Study 3 was to test if our hypotheses can be generalised to perceived environmental responsibility of one's government and policy acceptability of citizens. Specifically, we aimed to test if the extent to which people think their government aims to minimise its environmental impact is related to environmental self-identity. Furthermore, we tested if environmental self-identity mediates the relationship between perceived environmental responsibility and the acceptability of governmental policy measures aiming to reduce environmental problems caused by fossil energy use.

\section{Participants and procedure}

We conducted an online study among a paid panel consisting of members from the general Dutch population in 2017. A total of 261 participants took part 
in the study. Age ranged from 16 to 78 years $(M=48$, $\mathrm{SD}=16.82$ ). Of the participants, $49 \%$ were male and $51 \%$ female. Participants filled out questions on their values, norms, perceived environmental responsibility of the government, and environmental self-identity, and they were asked to rate the acceptability of different policy measures. In the current study, we do not report the results for values and norms. The language of the questionnaire was Dutch.

\section{Measures}

Perceived governmental environmental responsibility We used similar items as in Studies 1 and 2 , but we adapted them to specifically relate to the government: "I think the government has the goal to minimalise its impact on the environment", "I think that the government has implemented policy and procedures to minimalise its impact on the environment", and "I think the government has stated in its mission to implement sustainable (pro-environmental) policy". Participants could answer on a scale from 1 (totally disagree) to 7 (totally agree). The internal consistency of the scale was good $(N=261, \alpha=0.84$, $M=4.22, S D=1.17)$.

Environmental self-identity We used the same items as in Study 1 to measure environmental selfidentity. The internal consistency of the scale was $\operatorname{good}(N=261, \alpha=0.93, M=4.86, S D=0.1 .24)$.

Policy acceptability We measured the acceptability of 24 policy measures that systematically varied on three factors, namely, the type of behaviour it targeted, the type of measure (push or pull), and how pull policies would be financed or how revenues of push policies would be allocated. By systematically varying the policies on these three factors, the importance of each factor for policy acceptability can be determined via a conjoint analysis (see Steg et al., 2006). Yet, in the current study, we simply focus on the mean score of all 24 policy measures. An example item is: The use of energy efficient appliances will be promoted by introducing a fee on energy inefficient appliances. The revenues of this policy measure will be allocated to general funds of the government. In this example, the policy measure focuses on energy
Table 5 Correlations between perceived environmental responsibility (PER), environmental self-identity (ESI), and policy acceptability (ACC)

\begin{tabular}{llll}
\hline & PER & ESI & ACC \\
\hline PER & - & & \\
ESI & $.38^{* *}$ & - & - \\
ACC & $.45^{* *}$ & $.50^{* *}$ & \\
\hline${ }^{* *} p<.01$ & & &
\end{tabular}

efficient appliances and was a push measure, and revenues are allocated to general public funds. See Appendix (Table 6) for a complete overview of the 24 policy measures. Participants were asked to indicate to what extent they find each policy measure acceptable on a scale from 1 (not at all acceptable) to 7 (very acceptable). We calculated the mean of all 24 policy measures $(N=261, \alpha=0.94, M=4.60, S D=1.01)$.

Results

We first tested the correlations between PER, ESI, and policy acceptability (see Table 5). Our results support Hypothesis 1: We found a positive correlation between PER and ESI. The stronger PER, the stronger one's ESI.

The preconditions to test mediation were met. Specifically, the independent variable (PER) is related to the mediator (ESI) and that the mediator is related to the dependent variable (policy acceptability) (see Fig. 3). We found support for Hypothesis 2. PER and ESI explain $33 \%$ of the variance in policy acceptability $(F(2,258)=62.89, p<0.001)$. The indirect effect of PER on policy acceptability via ESI $(a * b)$ is 0.13 and significant; the $95 \%$ confidence interval ranges from 0.07 to 0.20 . We found complementary mediation, suggesting that ESI mediates the relationship between PER and policy acceptability, but there may be other mediators as well (Zhao et al., 2010).

\section{Discussion Study 3}

In Study 3, we found that the more people think their government aims to minimise its environmental impact, the stronger their environmental self-identity. A stronger environmental self-identity is in turn 
Fig. 3 The relationship between perceived environmental responsibility, environmental self-identity, and policy acceptability

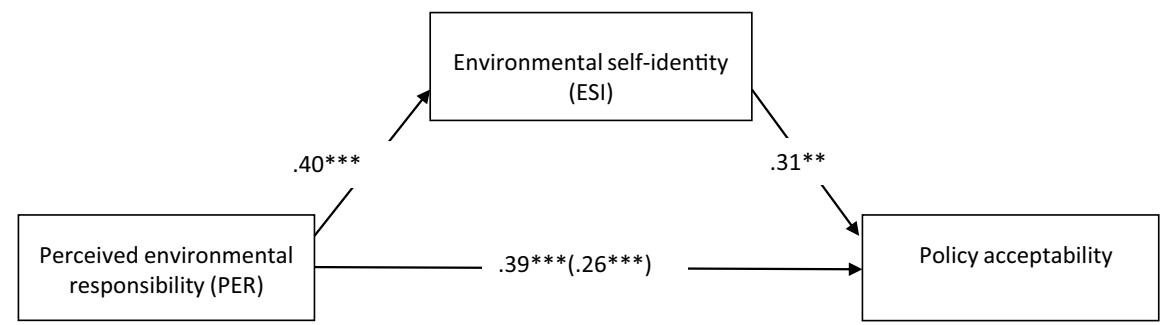

related to a stronger acceptability of policies aiming to reduce environmental problems. In Study 3, we replicated the findings from Study 1 and Study 2 . However, this time, we focused on citizens and their government instead of an organisation. We again found that the relationship between perceived environmental responsibility and environmental self-identity is medium (Cohen, 1988). We found support for complementary mediation, suggesting that there may be other factors as well that explain the relationship between perceived environmental responsibility and policy acceptability.

\section{General discussion}

In the current paper, we tested if perceived environmental responsibility of an organisation or government is related to the extent to which people see themselves as a pro-environmental person, and whether this in turn is related to a range of pro-environmental preferences and behaviours. We hypothesised that a stronger perceived environmental responsibility is related to a stronger environmental self-identity. Furthermore, we hypothesised that environmental self-identity mediates the relationship between perceived environmental responsibility and environmental preferences and behaviour. We found support for our hypotheses in all three studies. Specifically, we found that the more people think the organisation aims to minimise its environmental impact, the more they see themselves as a pro-environmental person. Importantly, we found support for this relationship among employees and customers of organisations, as well as among citizens in relation to their national government. Furthermore, we found support for our hypothesis that a stronger environmental self-identity is in turn related to a range of pro-environmental preferences and behaviour, such as energy use behaviour, the sustainable use of an electric vehicle, the acceptability of pro-environmental policies, and proenvironmental actions in general.

The strength of the relationship between the extent to which people see their organisation or government as pro-environmental and the extent to which they see themselves as a pro-environmental person was of a medium size in all studies (see Cohen, 1988). However, the amount of variance of each individual preference or behaviour explained by perceived environmental responsibility and environmental self-identity was rather low. This is probably because perceived environmental responsibility and environmental selfidentity are general determinants of pro-environmental behaviour; general antecedents generally explain less variance in behaviour than behaviour-specific determinants (Ajzen, 1996). Yet, importantly, general predictors are related to many preferences and behaviours, although the relationship with each preference or behaviour is weak (Van der Werff \& Steg, 2015). We indeed found that perceived environmental responsibility and environmental self-identity are related to many preferences and behaviours, including sustainable use of the electric vehicle, general proenvironmental actions, energy use behaviours, and the acceptability of pro-environmental policies. Interventions targeting these general predictors of environmental preferences and behaviours are likely to change each environmental behaviour only to a small extent. However, as environmental self-identity influences many behaviours, the overall environmental impact may be large. Importantly, we extend previous research by finding that perceived environmental responsibility is related to a wide range of pro-environmental behaviours outside of work, among customers and citizens (c.f., Dahiya, 2020; Norton et al., 2014; Ruepert et al., 2017). 
We argued that a stronger perceived environmental responsibility of one's organisation or government is related to a stronger environmental self-identity, as people identify with these organisations or government. Our findings are in line with social identity theory, which states that the groups people are part of influence how they see themselves (Tajfel \& Turner, 1979). However, one could argue that the relationship is the other way around. Namely, that those with a stronger environmental self-identity are more likely to work or be a customer at an organisation with a stronger perceived environmental responsibility. Interestingly, we also found that perceived environmental responsibility is related to environmental selfidentity among customers who could not choose to be a customer at that organisation. Furthermore, we found perceived environmental responsibility of one's government is related to environmental self-identity as well. People cannot choose their government: It simply depends on where they live. Therefore, these findings suggest that an alternative explanation, that those with a stronger environmental self-identity are more likely to choose an organisation or government that aims to minimise its environmental impact, cannot fully explain our findings. Instead, our findings suggest that perceived environmental responsibility of an organisation or government influences environmental self-identity.

Another alternative explanation for our findings may be that the stronger one's environmental self-identity, the more likely they are to see others as pro-environmental, including organisations or governments. Future research is needed to test our hypotheses using experimental designs to test causality. For example, perceived environmental responsibility could be manipulated, and the effects on environmental self-identity and environmental behaviour can be tested. However, research suggests that it may be difficult to manipulate the perceived environmental responsibility as people already have perceptions of their organisation (Ruepert et al., 2017). Therefore, it may be difficult to test these research questions in experimental designs. However, vignette studies including descriptions of hypothetical organisations could be used to test causality.

We found that perceived environmental responsibility is not only related to the behaviour of the employees working at that organisation, but also to the behaviour of customers of that organisation. Furthermore, citizens are more likely to see themselves as a pro-environmental person and therefore accept environmental policies when they perceive their government to be pro-environmental. Our findings are in line with previous research showing that perceived environmental responsibility of organisations or governments is positively related to pro-environmental behaviour of its employees or citizens (e.g. Ruepert et al., 2017; Rabinovich et al., 2012). We extended this research by testing the relationship among customers as well. Furthermore, we showed that perceived environmental responsibility of organisations and government is related to environmental behaviour and policy acceptability via environmental self-identity. As such, we test the process whereby perceived environmental responsibility is related to environmental actions.

We found support for indirect only and complementary mediation between perceived environmental responsibility and environmental action (Zhao et al., 2010). Indirect only mediation suggests that perceived environmental responsibility is only indirectly related to environmental action via environmental self-identity, not directly. Complementary mediation suggests that environmental self-identity mediates the relationship between perceived environmental responsibility and environmental actions. As such, there may be other mechanisms that explain the relationship between perceived environmental responsibility and environmental behaviour. For example, perceived environmental responsibility may influence the extent to which employees think their colleagues engage in pro-environmental behaviour (i.e. descriptive social norms), which may in turn influence their environmental behaviour (Cialdini et al., 1990). Future research is needed to test other mechanisms that explain the relationship between perceived environmental responsibility and environmental behaviour, in addition to environmental self-identity.

Furthermore, one may argue that perceived environmental responsibility is particularly likely to influence environmental self-identity and environmental behaviour when people strongly identify with the organisation or government. Research indeed suggests that the stronger people identify with a 
pro-environmental organisation, the more likely they are to act pro-environmental (Sloot et al., 2018). In the current studies, we did not test to what extent people identify with their organisation or government. Future research can test if perceived environmental responsibility is more strongly related to environmental self-identity and environmental behaviour when identification with the organisation or government is stronger.

Our findings have important practical implications. They suggest that organisations and governments can affect pro-environmental behaviour of people by minimising their own environmental impact. Specifically, organisations and governments could reduce their environmental impact and communicate their pro-environmental mission and activities to their employees, customers, and citizens (Bouman \& Steg, 2019). When an organisation has many employees or customers, the extent to which it aims and shows to minimise its environmental impact may influence the behaviour of many people. The more organisations and governments aim and show to be proenvironmental, the stronger perceived environmental responsibility is likely to be; therefore, people are more likely to see themselves as pro-environmental, which in turn increases their pro-environmental preferences and behaviour. However, research suggests that people may be sceptical about organisations claiming to minimise their environmental impact (Goh \& Balaji, 2016). The more sceptical people are about such claims, the less likely they are to engage in the purchase of pro-environmental products. Therefore, it is crucial that organisations and governments are transparent about their environmental impact to reduce scepticism. Organisations may also communicate that they are environmentally responsible while they hardly take action to reduce their environmental impact (e.g. Laufer, 2003), known as greenwashing. Research suggests that greenwashing decreases the likelihood that consumers will buy pro-environmental products from the organisation (Zhang et al., 2018). As such, organisations should be careful that they do act pro-environmentally when they communicate their intention to be environmentally responsible.

In conclusion, to reduce environmental problems, it is important that citizens, governments, and organisations take action to minimise their environmental impact. Our findings suggest that the more people think organisations or governments try to reduce their environmental impact, the more people see themselves as a pro-environmental person, which in turn is related to a range of pro-environmental actions. Therefore, if organisations and governments take action to reduce their environmental impact, customers, employees, and citizens may also be more likely to do so too.

Funding This paper was made possible by funding received from the European Union's Horizon 2020 research and innovation program under grant agreement no. 723791 and funding received from NWO for the projects I-PRISM and SMARTEST (Grant No. 408.URS + 0.16.010 1813).

\section{Declarations}

Conflict of Interest The authors declare no competing interests.

Open Access This article is licensed under a Creative Commons Attribution 4.0 International License, which permits use, sharing, adaptation, distribution and reproduction in any medium or format, as long as you give appropriate credit to the original author(s) and the source, provide a link to the Creative Commons licence, and indicate if changes were made. The images or other third party material in this article are included in the article's Creative Commons licence, unless indicated otherwise in a credit line to the material. If material is not included in the article's Creative Commons licence and your intended use is not permitted by statutory regulation or exceeds the permitted use, you will need to obtain permission directly from the copyright holder. To view a copy of this licence, visit http://creativecommons.org/licenses/by/4.0/. 


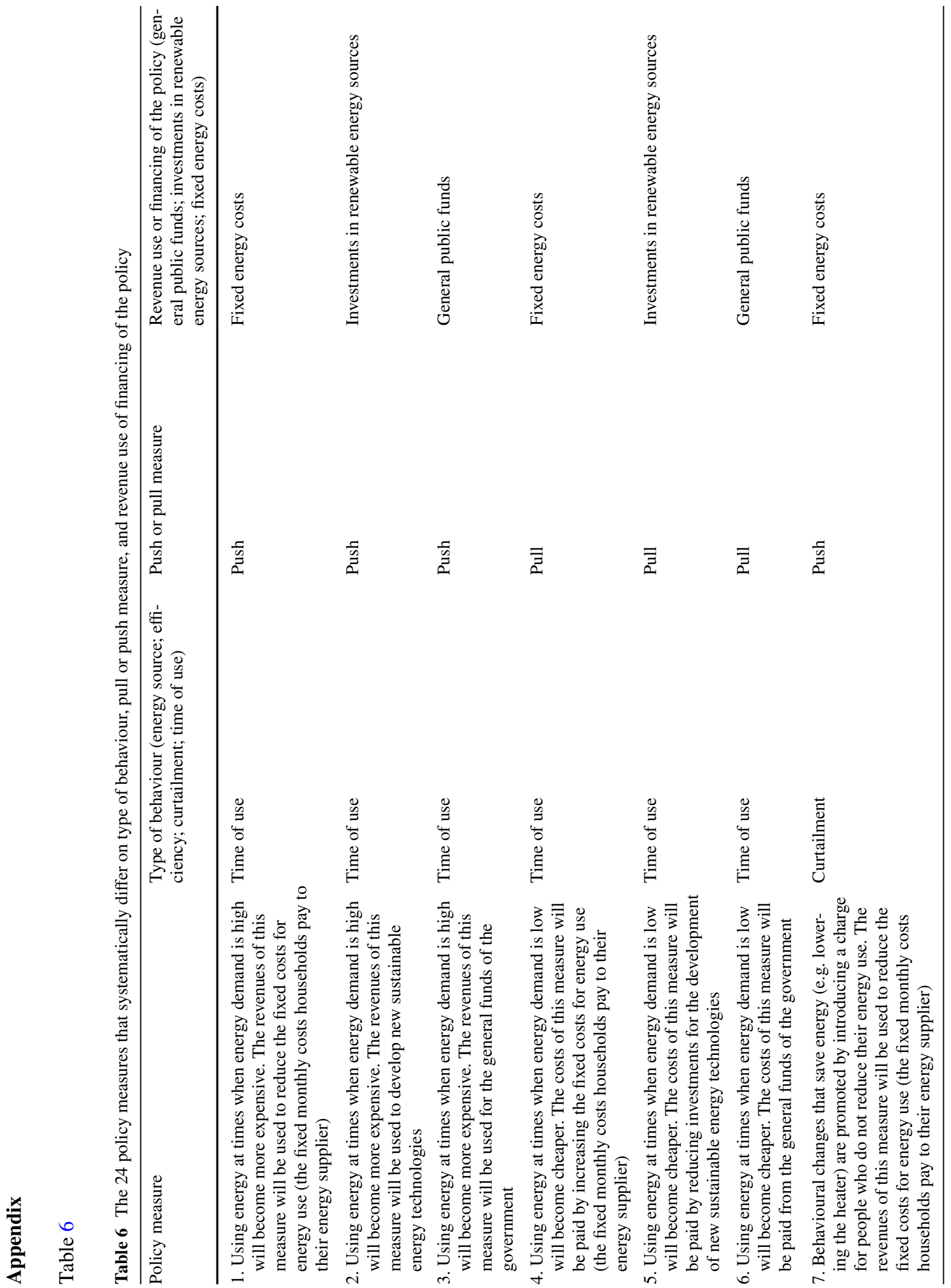




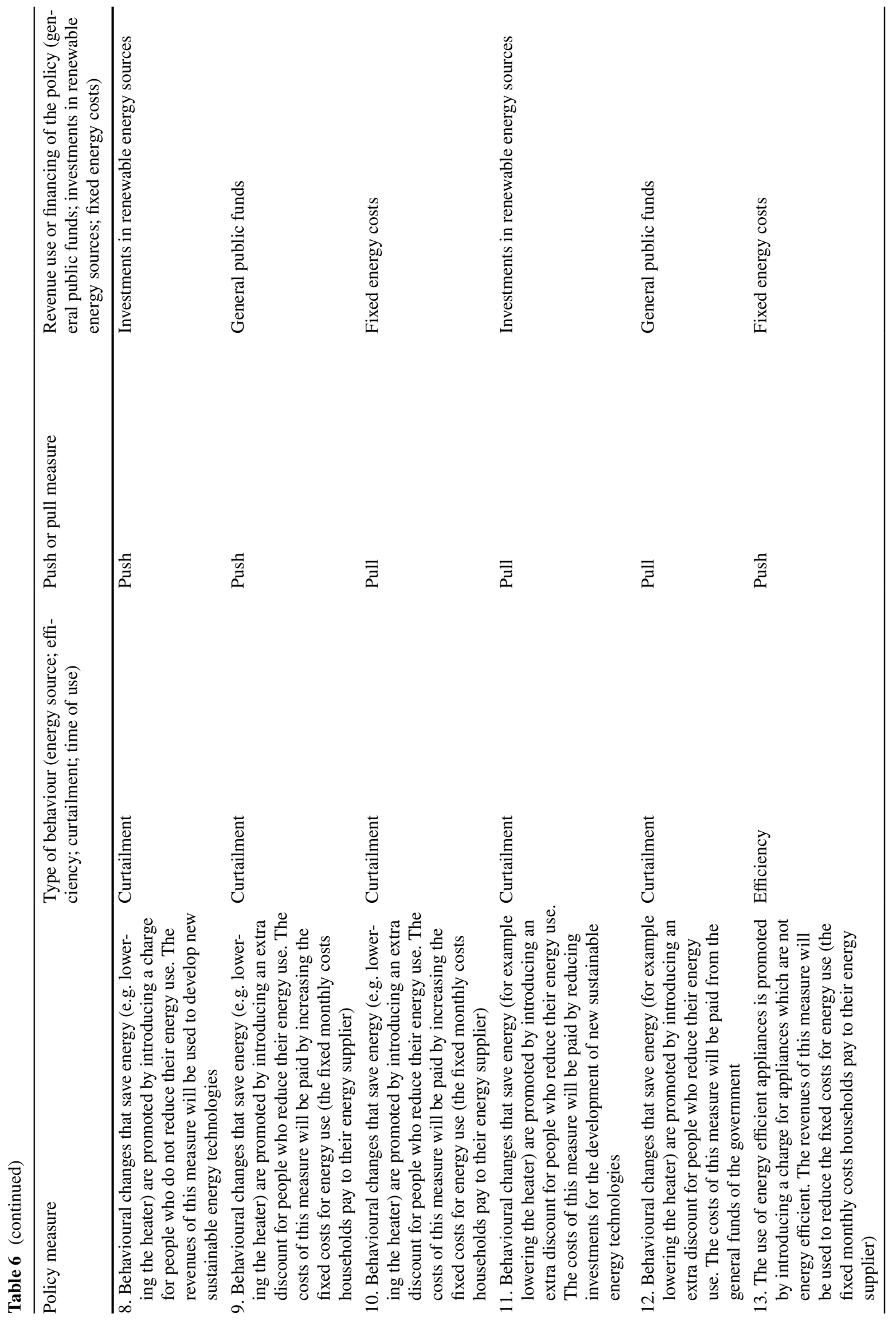



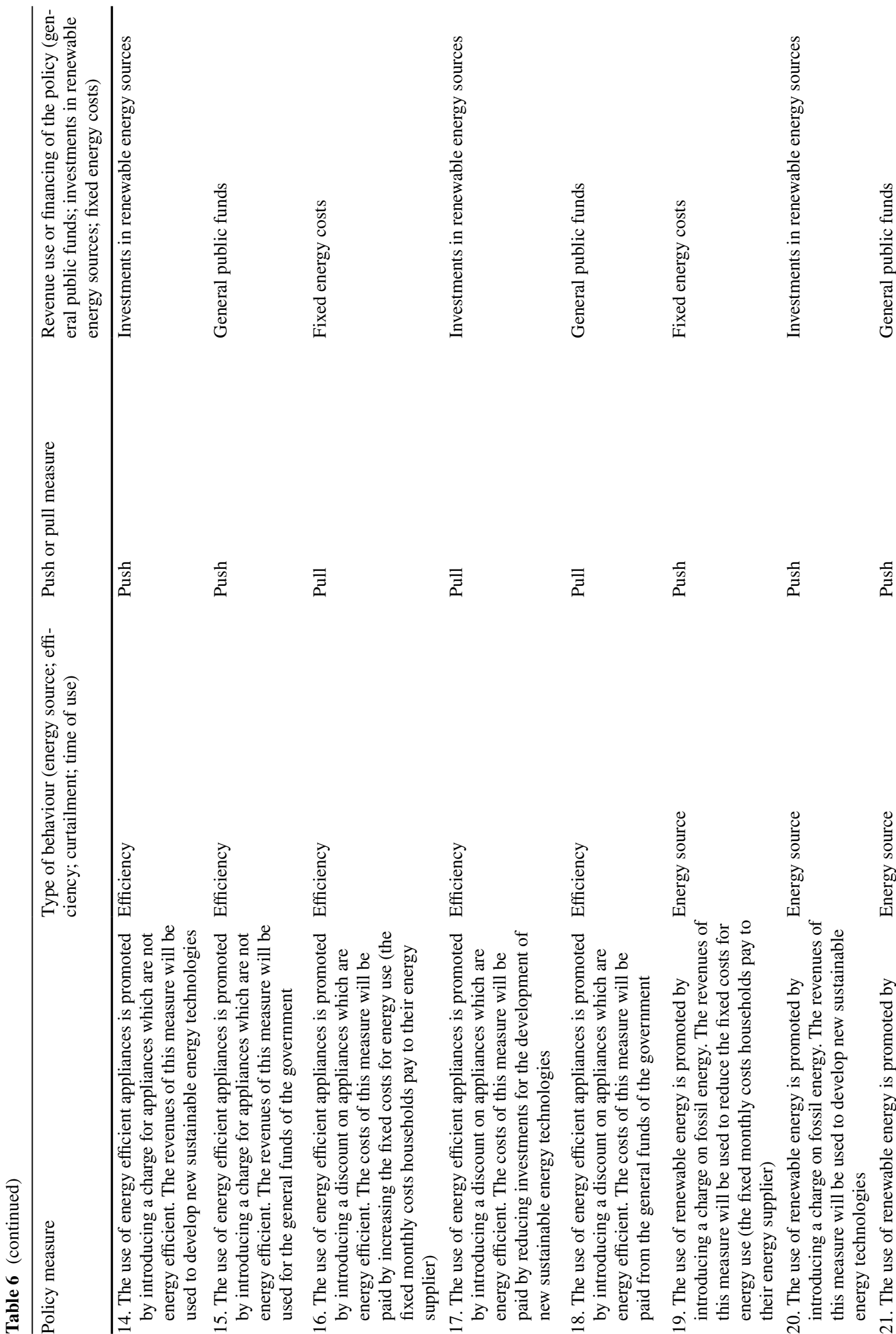

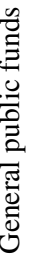

$\stackrel{5}{5}$

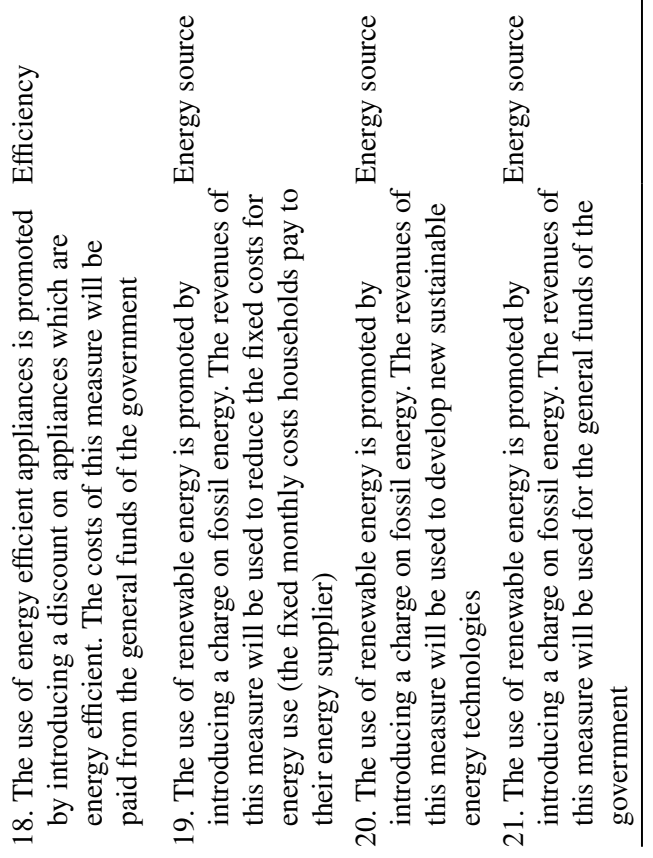




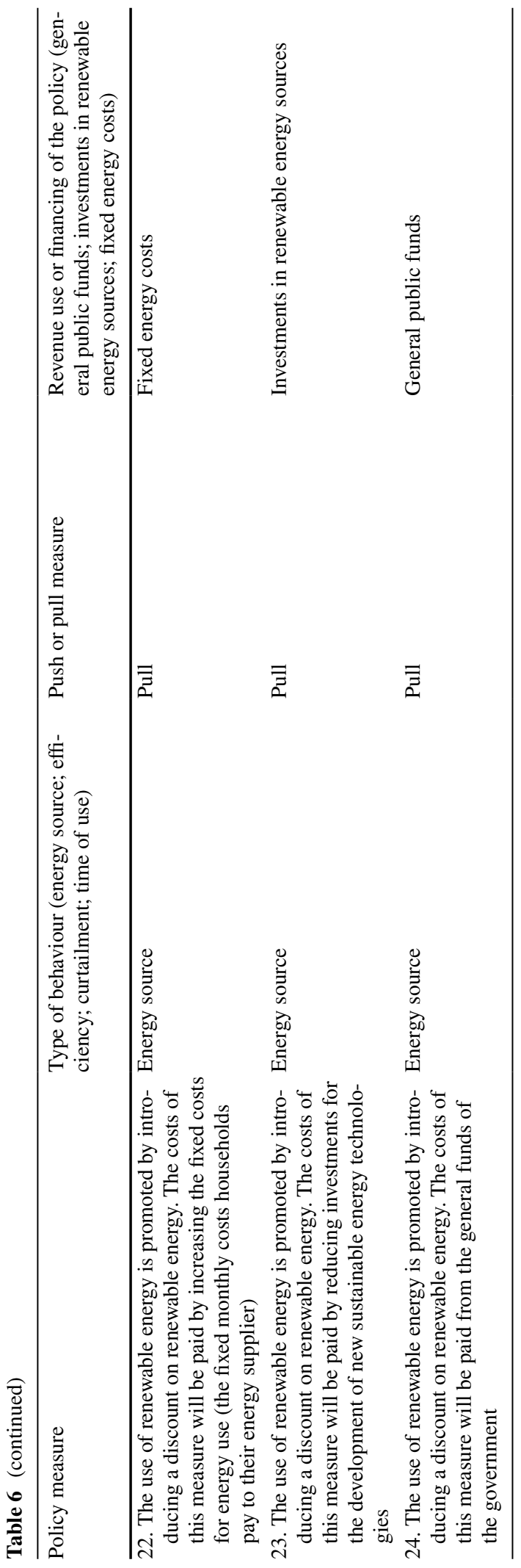




\section{References}

Ajzen, I. (1996). The directive influence of attitudes on behavior. In P. M. Gollwitzer \& J. A. Bargh (Eds.), Psychology of action (pp. 385-403). Guilford Press.

Benders, R. M., Kok, R., Moll, H. C., Wiersma, G., \& Noorman, K. J. (2006). New approaches for household energy conservation-In search of personal household energy budgets and energy reduction options. Energy Policy, 34(18), 3612-3622.

Boogen, N., Daminato, C., \& Van der Werff, E (2018) Large sample survey. Retrieved from http://www.penny-project. eu/wp-content/uploads/2018/03/PENNY_D1.3.pdf.

Bouman, T., \& Steg, L. (2019). Motivating society-wide proenvironmental change. One. Earth, 1(1), 27-30.

Cialdini, R. B., Reno, R. R., \& Kallgren, C. A. (1990). A focus theory of normative conduct: Recycling the concept of norms to reduce littering in public places. Journal of Personality and Social Psychology, 58(6), 1015-1026.

Cohen, J. (1988). Statistical power analysis for the behavioral sciences. . Routledge.

Dahiya, R. (2020). Does organisational sustainability policies affect environmental attitude of employees? The missing link of green work climate perceptions. Business Strategy \& Development, 3(3), 395-403.

De Vries, G., Terwel, B. W., Ellemers, N., \& Daamen, D. D. (2015). Sustainability or profitability? How communicated motives for environmental policy affect public perceptions of corporate greenwashing. Corporate Social Responsibility and Environmental Management, 22(3), 142-154.

Dietz, T., Frank, K. A., Whitley, C. T., Kelly, J., \& Kelly, R. (2015). Political influences on greenhouse gas emissions from US states. Proceedings of the National Academy of Sciences, 112(27), 8254-8259.

Elf, P., Isham, A., \& Gatersleben, B. (2020). Above and beyond? How businesses can drive sustainable development by promoting lasting pro-environmental behaviour change: An examination of the IKEA Live Lagom project. Business Strategy and the Environment. https://doi.org/10. 1002/bse.2668.

European Automobile Manufacturers Association, Alternative Fuel Vehicle Registrations, (2017). (October 5, 2018) Retrieved from, http://www.acea.be/pressreleases/article/ alternative-fuel-vehicle-registrations-37.6-in-first-quart er-of-2017.

Eurostat (2017). Accessed on 23 August 2019 via http://appsso. eurostat.ec.europa.eu/nui/show.do?dataset=ilc_lvph01\& lang=en

Fielding, K. S., \& Hornsey, M. J. (2016). A social identity analysis of climate change and environmental attitudes and behaviors: Insights and opportunities. Frontiers in Psychology, 7, 121.

Gatersleben, B., Murtagh, N., \& Abrahamse, W. (2014). Values, identity and pro-environmental behaviour. Contemporary Social Science, 9(4), 374-392.

Goh, S. K., \& Balaji, M. S. (2016). Linking green skepticism to green purchase behavior. Journal of Cleaner Production, 131, 629-638.
Hayes, A. F. (2017). Introduction to mediation, moderation, and conditional process analysis: A regression-based approach. Guilford Publications.

Heikkurinen, P., Young, C. W., \& Morgan, E. (2019). Business for sustainable change: Extending eco-efficiency and ecosufficiency strategies to consumers. Journal of Cleaner Production, 218, 656-664.

IPCC. (2018). Summary for policymakers. In V. Masson-Delmotte, P. Zhai, H.-O. Pörtner, D. Roberts, J. Skea, P. R. Shukla, A. Pirani, W. Moufouma-Okia, C. Péan, R. Pidcock, S. Connors, J. B. R. Matthews, Y. Chen, X. Zhou, M.I. Gomis, E. Lonnoy, T. Maycock, M. Tignor, \& T. Waterfield (Eds.), Global warming of $1.5^{\circ} \mathrm{C}$. An IPCC special report on the impacts of global warming of $1.5^{\circ} \mathrm{C}$ above pre-industrial levels and related global greenhouse gas emission pathways, in the context of strengthening the global response to the threat of climate change, sustainable development, and efforts to eradicate poverty (pp. 32). World Meteorological Organization.

Laufer, W. S. (2003). Social accountability and corporate greenwashing. Journal of Business Ethics, 43(3), 253-261.

Lichtenstein, D. R., Drumwright, M. E., \& Braig, B. M. (2004). The effect of corporate social responsibility on customer donations to corporate-supported nonprofits. Journal of Marketing, 68(4), 16-32.

Namazkhan, M., Albers, C., \& Steg, L. (2019). The role of environmental values, socio-demographics and building characteristics in setting room temperatures in winter. Energy, 171, 1183-1192.

Nicolson, M., Huebner, G. M., Shipworth, D., \& Elam, S. (2017). Tailored emails prompt electric vehicle owners to engage with tariff switching information. Nature Energy, 2(6), 17073.

Norton, T. A., Zacher, H., \& Ashkanasy, N. M. (2014). Organisational sustainability policies and employee green behaviour: The mediating role of work climate perceptions. Journal of Environmental Psychology, 38, 49-54.

Rabinovich, A., Morton, T. A., Postmes, T., \& Verplanken, B. (2012). Collective self and individual choice: The effects of inter-group comparative context on environmental values and behaviour. British Journal of Social Psychology, 51(4), 551-569.

Rogers, E. M. (2010). Diffusion of Innovations (5th ed.). Simon and Schuster.

Ruepert, A. M., Keizer, K., \& Steg, L. (2017). The relationship between corporate environmental responsibility, employees' biospheric values and pro-environmental behaviour at work. Journal of Environmental Psychology, 54, 65-78.

Sloot, D., Jans, L., \& Steg, L. (2018). Can community energy initiatives motivate sustainable energy behaviours? The role of initiative involvement and personal pro-environmental motivation. Journal of Environmental Psychology, 57, 99-106.

Sovacool, B. K. (2014). Diversity: Energy studies need social science. Nature, 511, 529-530. https://doi.org/10.1038/ 511529a

Steg, L., Dreijerink, L., \& Abrahamse, W. (2006). Why are energy policies acceptable and effective? Environment and Behavior, 38(1), 92-111. 
Tajfel, H., \& Turner, J. C. (1979). In: W. G. Austin \& S. Worchel (Eds.), The social identity of intergroup relations (pp. 33-47). Brooks-Cole.

Thøgersen, J. (2018). Frugal or green? Basic drivers of energy saving in European households. Journal of Cleaner Production, 197, 1521-1530.

Vaccaro, A., \& Echeverri, D. P. (2010). Corporate transparency and green management. Journal of Business Ethics, 95(3), 487-506.

Van der Werff, E., \& Steg, L. (2015). One model to predict them all: Predicting energy behaviours with the norm activation model. Energy Research \& Social Science, 6, 8-14.

Van der Werff, E., Steg, L., \& Keizer, K. (2013). The value of environmental self-identity: The relationship between biospheric values, environmental self-identity and environmental preferences, intentions and behaviour. Journal of Environmental Psychology, 34, 55-63.

Van der Werff, E., Steg, L., \& Keizer, K. (2014). I am what I am, by looking past the present: Rhe influence of biospheric values and past behavior on environmental selfidentity. Environment and Behavior, 46(5), 626-657.
Victor, D. (2015). Climate change: Embed the social sciences in climate policy. Nature, 520(7545), 27-29.

Whitmarsh, L., \& O’Neill, S. (2010). Green identity, green living? The role of pro-environmental self-identity in determining consistency across diverse pro-environmental behaviours. Journal of Environmental Psychology, 30(3), 305-314.

Zhang, L., Li, D., Cao, C., \& Huang, S. (2018). The influence of greenwashing perception on green purchasing intentions: The mediating role of green word-of-mouth and moderating role of green concern. Journal of Cleaner Production, 187, 740-750.

Zhao, X., Lynch, J. G., Jr., \& Chen, Q. (2010). Reconsidering Baron and Kenny: Myths and truths about mediation analysis. Journal of Consumer Research, 37(2), 197-206.

Publisher's Note Springer Nature remains neutral with regard to jurisdictional claims in published maps and institutional affiliations. 